\title{
Brain transcriptome analysis of a familial Alzheimer's disease-like mutation in the zebrafish presenilin 1 gene implies effects on energy production
}

\author{
Morgan Newman ${ }^{\dagger}$, Nhi Hin ${ }^{\dagger}$, Stephen Pederson and Michael Lardelli ${ }^{*}$ (i)
}

\begin{abstract}
To prevent or ameliorate Alzheimer's disease (AD) we must understand its molecular basis. AD develops over decades but detailed molecular analysis of AD brains is limited to postmortem tissue where the stresses initiating the disease may be obscured by compensatory responses and neurodegenerative processes. Rare, dominant mutations in a small number of genes, but particularly the gene PRESENILIN 1 (PSEN1), drive early onset of familial $A D$ (EOfAD). Numerous transgenic models of AD have been constructed in mouse and other organisms, but transcriptomic analysis of these models has raised serious doubts regarding their representation of the disease state. Since we lack clarity regarding the molecular mechanism(s) underlying AD, we posit that the most valid approach is to model the human EOfAD genetic state as closely as possible. Therefore, we sought to analyse brains from zebrafish heterozygous for a single, EOfAD-like mutation in their PSEN1-orthologous gene, psen 1. We previously introduced an EOfAD-like mutation (Q96_K97del) into the endogenous psen 1 gene of zebrafish. Here, we analysed transcriptomes of young adult (6-month-old) entire brains from a family of heterozygous mutant and wild type sibling fish. Gene ontology (GO) analysis implies effects on mitochondria, particularly ATP synthesis, and on ATP-dependent processes including vacuolar acidification.
\end{abstract}

Keywords: Alzheimer's disease, Presenilin 1, Mutation, Transcriptome, Brain, ATP synthesis, Mitochondria, Vacuolar acidification, Zebrafish, Genome editing

\section{Background}

$\mathrm{AD}$ is the most common form of dementia with severe personal, social, and economic impacts. Rare, familial forms of $\mathrm{AD}$ exist caused by autosomal dominant mutations in single genes (reviewed by [1]). The majority of these mutations occur in the gene PRESENILIN 1 (PSEN1) that encodes a multipass integral membrane protein involved in intra-membrane cleavage of numerous proteins [1].

A wide variety of transgenic models of $\mathrm{AD}$ have been created and studied. These are aimed at reproducing histopathologies posited to be central to the disease process, i.e. amyloid plaques and neurofibrillary tangles

\footnotetext{
* Correspondence: Michael.lardelli@adelaide.edu.au

${ }^{+}$Morgan Newman and Nhi Hin are equal first authors.

Department of Molecular and Biomedical Science, University of Adelaide,

School of Biological Sciences, North Terrace, Adelaide, SA 5005, Australia
}

of the protein MAPT [2]. However, analysis of the effects on the brain transcriptome of the transgenes driving a number of these mouse models showed little concordance with transcriptomic differences between human AD brains and age-matched controls [3] (although a recent study asserts that this lack of concordance for the popular "5XFAD" transgenic mouse model is due to previous failure to analyse the effects of its transgenes in a variety of genetic backgrounds [4]). We posit that, in the absence of an understanding of the molecular mechanism(s) underlying $\mathrm{AD}$, the most objective approach to modeling this disease (or, at least, modeling its genetic form, EOfAD) is to create a genetic state as similar as possible to the EOfAD state in humans. Mouse "knock-in" models of EOfAD mutations were created over a decade ago and showed subtle phenotypic effects but not the desired histopathologies (e.g. [5, 6]).

(c) The Author(s). 2019 Open Access This article is distributed under the terms of the Creative Commons Attribution 4.0 International License (http://creativecommons.org/licenses/by/4.0/), which permits unrestricted use, distribution, and reproduction in any medium, provided you give appropriate credit to the original author(s) and the source, provide a link to the Creative Commons license, and indicate if changes were made. The Creative Commons Public Domain Dedication waiver (http://creativecommons.org/publicdomain/zero/1.0/) applies to the data made available in this article, unless otherwise stated. 
Table 1 GOs enriched for genes differentially expressed between heterozygous mutant and wild type sibling fish brains

\begin{tabular}{|c|c|c|c|c|c|}
\hline Gene Ontology Term & Ontology & Total Genes & DE Genes & $\mathrm{p}$-value & FDR $p$-value \\
\hline ATP biosynthetic process & $\mathrm{BP}$ & 29 & 7 & 3.48987E-08 & 0.00041 \\
\hline ribonucleoside triphosphate biosynthetic process & $\mathrm{BP}$ & 49 & 8 & 9.41317E-08 & 0.00045 \\
\hline nucleoside triphosphate biosynthetic process & $\mathrm{BP}$ & 54 & 8 & 2.06555E-07 & 0.00060 \\
\hline purine nucleoside triphosphate biosynthetic process & $\mathrm{BP}$ & 41 & 7 & 4.46237E-07 & 0.00060 \\
\hline purine ribonucleoside triphosphate biosynthetic process & $\mathrm{BP}$ & 41 & 7 & 4.46237E-07 & 0.00060 \\
\hline hydrogen transport & $\mathrm{BP}$ & 60 & 8 & $4.783 \mathrm{E}-07$ & 0.00060 \\
\hline proton transport & $\mathrm{BP}$ & 60 & 8 & 4.783E-07 & 0.00060 \\
\hline energy coupled proton transport, down electrochemical gradient & $\mathrm{BP}$ & 27 & 6 & $5.89038 \mathrm{E}-07$ & 0.00060 \\
\hline ATP synthesis coupled proton transport & $\mathrm{BP}$ & 27 & 6 & $5.89038 \mathrm{E}-07$ & 0.00060 \\
\hline transport & $\mathrm{BP}$ & 2072 & 48 & $2.11748 \mathrm{E}-06$ & 0.00165 \\
\hline purine nucleoside monophosphate biosynthetic process & $\mathrm{BP}$ & 54 & 7 & 3.09019E-06 & 0.00172 \\
\hline purine ribonucleoside monophosphate biosynthetic process & $\mathrm{BP}$ & 54 & 7 & 3.09019E-06 & 0.00172 \\
\hline hydrogen ion transmembrane transport & $\mathrm{BP}$ & 54 & 7 & 3.09019E-06 & 0.00172 \\
\hline ribonucleoside triphosphate metabolic process & $\mathrm{BP}$ & 133 & 10 & $3.8448 \mathrm{E}-06$ & 0.00178 \\
\hline establishment of localization & $\mathrm{BP}$ & 2123 & 48 & 4.20295E-06 & 0.00182 \\
\hline ATP metabolic process & $\mathrm{BP}$ & 109 & 9 & $5.50772 \mathrm{E}-06$ & 0.00230 \\
\hline nucleoside triphosphate metabolic process & $\mathrm{BP}$ & 140 & 10 & $6.08925 \mathrm{E}-06$ & 0.00245 \\
\hline cation transport & $\mathrm{BP}$ & 452 & 18 & $6.61154 \mathrm{E}-06$ & 0.00258 \\
\hline monovalent inorganic cation transport & BP & 219 & 12 & $1.10729 \mathrm{E}-05$ & 0.00392 \\
\hline ribonucleoside monophosphate biosynthetic process & $\mathrm{BP}$ & 65 & 7 & $1.08944 \mathrm{E}-05$ & 0.00392 \\
\hline nucleoside monophosphate biosynthetic process & $\mathrm{BP}$ & 68 & 7 & 1.47269E-05 & 0.00492 \\
\hline purine ribonucleoside triphosphate metabolic process & $\mathrm{BP}$ & 125 & 9 & $1.68142 \mathrm{E}-05$ & 0.00546 \\
\hline purine nucleoside triphosphate metabolic process & $\mathrm{BP}$ & 126 & 9 & 1.79263E-05 & 0.00552 \\
\hline transmembrane transport & $\mathrm{BP}$ & 654 & 21 & $2.93288 \mathrm{E}-05$ & 0.00797 \\
\hline purine nucleoside monophosphate metabolic process & $\mathrm{BP}$ & 136 & 9 & $3.2951 \mathrm{E}-05$ & 0.00837 \\
\hline purine ribonucleoside monophosphate metabolic process & BP & 136 & 9 & $3.2951 \mathrm{E}-05$ & 0.00837 \\
\hline energy coupled proton transmembrane transport, against electrochemical gradient & $\mathrm{BP}$ & 35 & 5 & $5.20342 \mathrm{E}-05$ & 0.01106 \\
\hline ATP hydrolysis coupled proton transport & $\mathrm{BP}$ & 35 & 5 & $5.20342 \mathrm{E}-05$ & 0.01106 \\
\hline ATP hydrolysis coupled transmembrane transport & $\mathrm{BP}$ & 35 & 5 & $5.20342 \mathrm{E}-05$ & 0.01106 \\
\hline ATP hydrolysis coupled ion transmembrane transport & $\mathrm{BP}$ & 35 & 5 & $5.20342 \mathrm{E}-05$ & 0.01106 \\
\hline ATP hydrolysis coupled cation transmembrane transport & $\mathrm{BP}$ & 35 & 5 & $5.20342 \mathrm{E}-05$ & 0.01106 \\
\hline ion transport & $\mathrm{BP}$ & 737 & 22 & $5.61478 \mathrm{E}-05$ & 0.01152 \\
\hline localization & $\mathrm{BP}$ & 2621 & 52 & $6.0913 \mathrm{E}-05$ & 0.01207 \\
\hline ribonucleoside monophosphate metabolic process & $\mathrm{BP}$ & 147 & 9 & $6.06496 \mathrm{E}-05$ & 0.01207 \\
\hline nucleoside monophosphate metabolic process & $\mathrm{BP}$ & 150 & 9 & 7.09445E-05 & 0.01360 \\
\hline single-organism localization & $\mathrm{BP}$ & 819 & 23 & 9.51294E-05 & 0.01738 \\
\hline single-organism transport & $\mathrm{BP}$ & 776 & 22 & 0.000119082 & 0.02109 \\
\hline ribonucleotide biosynthetic process & $\mathrm{BP}$ & 129 & 8 & 0.000143028 & 0.02423 \\
\hline ribose phosphate biosynthetic process & $\mathrm{BP}$ & 129 & 8 & 0.000143028 & 0.02423 \\
\hline vacuolar acidification & $\mathrm{BP}$ & 11 & 3 & 0.000246582 & 0.04101 \\
\hline ribonucleotide metabolic process & $\mathrm{BP}$ & 220 & 10 & 0.000281352 & 0.04506 \\
\hline proton-transporting two-sector ATPase complex, proton-transporting domain & $\mathrm{CC}$ & 25 & 6 & 3.59375E-07 & 0.00060 \\
\hline proton-transporting two-sector ATPase complex & $\mathrm{CC}$ & 45 & 7 & 8.65692E-07 & 0.00078 \\
\hline mitochondrial membrane & $\mathrm{CC}$ & 285 & 15 & 1.42199E-06 & 0.00119 \\
\hline
\end{tabular}


Table 1 GOs enriched for genes differentially expressed between heterozygous mutant and wild type sibling fish brains (Continued)

\begin{tabular}{|c|c|c|c|c|c|}
\hline Gene Ontology Term & Ontology & Total Genes & DE Genes & $\mathrm{p}$-value & FDR $p$-value \\
\hline mitochondrial envelope & CC & 303 & 15 & $3.0322 \mathrm{E}-06$ & 0.00172 \\
\hline membrane part & $\mathrm{CC}$ & 4868 & 85 & $1.1722 \mathrm{E}-05$ & 0.00403 \\
\hline organelle membrane & CC & 789 & 24 & $1.84982 \mathrm{E}-05$ & 0.00555 \\
\hline mitochondrial inner membrane & CC & 195 & 11 & $1.97958 \mathrm{E}-05$ & 0.00579 \\
\hline integral component of membrane & CC & 4419 & 78 & $2.52479 \mathrm{E}-05$ & 0.00720 \\
\hline intrinsic component of membrane & CC & 4453 & 78 & 3.37749E-05 & 0.00840 \\
\hline organelle envelope & $\mathrm{CC}$ & 420 & 16 & $3.76291 \mathrm{E}-05$ & 0.00917 \\
\hline envelope & $\mathrm{CC}$ & 422 & 16 & 3.98337E-05 & 0.00950 \\
\hline organelle inner membrane & $\mathrm{CC}$ & 215 & 11 & $4.86028 \mathrm{E}-05$ & 0.01106 \\
\hline Cul2-RING ubiquitin ligase complex & $\mathrm{CC}$ & 7 & 3 & $5.4156 \mathrm{E}-05$ & 0.01131 \\
\hline proton-transporting ATP synthase complex & CC & 19 & 4 & $6.25883 \mathrm{E}-05$ & 0.01220 \\
\hline mitochondrial membrane part & CC & 117 & 8 & $7.21148 \mathrm{E}-05$ & 0.01360 \\
\hline mitochondrial part & $\mathrm{CC}$ & 404 & 15 & $8.83156 \mathrm{E}-05$ & 0.01639 \\
\hline membrane & CC & 5379 & 88 & 0.000106964 & 0.01924 \\
\hline vacuolar proton-transporting V-type ATPase, V0 domain & CC & 9 & 3 & 0.000127733 & 0.02229 \\
\hline mitochondrial proton-transporting ATP synthase complex, coupling factor F(o) & CC & 12 & 3 & 0.000325933 & 0.04885 \\
\hline proton-transporting V-type ATPase, V0 domain & $\mathrm{CC}$ & 12 & 3 & 0.000325933 & 0.04885 \\
\hline ATPase activity, coupled to transmembrane movement of ions, rotational mechanism & MF & 34 & 7 & $1.1446 \mathrm{E}-07$ & 0.00045 \\
\hline hydrogen ion transmembrane transporter activity & MF & 84 & 9 & $6.11883 \mathrm{E}-07$ & 0.00060 \\
\hline ATPase activity, coupled to transmembrane movement of substances & MF & 98 & 9 & 2.27123E-06 & 0.00166 \\
\hline $\begin{array}{l}\text { hydrolase activity, acting on acid anhydrides, catalyzing transmembrane movement } \\
\text { of substances }\end{array}$ & MF & 101 & 9 & $2.92425 \mathrm{E}-06$ & 0.00172 \\
\hline primary active transmembrane transporter activity & MF & 104 & 9 & 3.73269E-06 & 0.00178 \\
\hline P-P-bond-hydrolysis-driven transmembrane transporter activity & MF & 104 & 9 & $3.73269 \mathrm{E}-06$ & 0.00178 \\
\hline cation-transporting ATPase activity & MF & 56 & 7 & $3.96731 \mathrm{E}-06$ & 0.00178 \\
\hline ATPase coupled ion transmembrane transporter activity & MF & 56 & 7 & $3.96731 \mathrm{E}-06$ & 0.00178 \\
\hline ATPase activity, coupled to movement of substances & MF & 112 & 9 & $6.88692 \mathrm{E}-06$ & 0.00260 \\
\hline active ion transmembrane transporter activity & MF & 96 & 8 & 1.72916E-05 & 0.00546 \\
\hline active transmembrane transporter activity & MF & 281 & 13 & 2.87859E-05 & 0.00797 \\
\hline proton-transporting ATP synthase activity, rotational mechanism & MF & 16 & 4 & 3.02121E-05 & 0.00803 \\
\hline transporter activity & MF & 991 & 25 & 0.000249051 & 0.04101 \\
\hline substrate-specific transmembrane transporter activity & MF & 709 & 20 & 0.000263528 & 0.04279 \\
\hline ion transmembrane transporter activity & MF & 660 & 19 & 0.000293184 & 0.04572 \\
\hline substrate-specific transporter activity & MF & 828 & 22 & 0.000297009 & 0.04572 \\
\hline monovalent inorganic cation transmembrane transporter activity & MF & 264 & 11 & 0.000297217 & 0.04572 \\
\hline
\end{tabular}

GOs are grouped by ontology (BP, CC or MF) and ranked by FDR-corrected $p$-value

However, at that time, researchers did not have access to RNA-Seq technology. To the best of our knowledge, transcriptome analysis of the EOfAD mutation knock-in mouse models was never performed.

In humans, $\mathrm{AD}$ is thought to develop over decades and the median survival to onset age for EOfAD mutations in human PSEN1 considered collectively is 45 years [7]. Functional MRI of human children carrying EOfAD mutations in PSEN1 has revealed differences in brain activity compared to non-carriers in individuals as young as 9 years of age [8]. Presumably therefore, heterozygosity for EOfAD mutations in PSEN1 causes early molecular changes/stresses that eventually lead to AD.

Transcriptome analysis is currently the most detailed molecular phenotypic analysis possible on cells or tissues. Here we present an initial analysis of the transcriptomic differences caused in young adult (6-month-old) zebrafish brains by the presence of an EOfAD-like mutation in the 
gene $p \operatorname{sen} 1$ that is orthologous to the human PSEN1 gene. $\mathrm{GO}$ analysis supports very significant effects on mitochondrial function, especially synthesis of ATP, and on ATP-dependent functions such as the acidification of lysosomes that are critical for autophagy.

\section{Materials and methods}

The mutant allele, Q96_K97del, of psen1 was a byproduct identified during our introduction of the K97fs mutation into psen 1 (that models the K115fs mutation of human PSEN2 - see [9] for an explanation).

Q96_K97del is a deletion of 6 nucleotides from the coding sequence of the psen 1 gene. This is predicted to distort the first lumenal loop of the Psen1 protein. In this sense, it is similar to a number of EOfAD mutations of human PSEN1 [10]. Also, in common with all the widely distributed EOfAD mutations in PSEN1, (and consistent with the PRESENILIN EOfAD mutation "reading frame preservation rule" [1]), the Q96_K97del allele is predicted to encode a transcript that includes the C-terminal sequences of the wild type protein. Therefore, as a model of an EOfAD mutation, it is superior to the K97fs mutation in psen1 [9].

To generate a family of heterozygous Q96_K97del al-

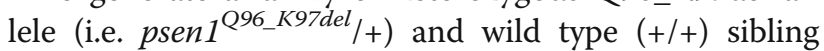
fish, we mated a psen1 $1^{\text {Q96_K97del } /+}$ individual with a $+/+$ individual and raised the progeny from a single spawning event together in one tank. Zebrafish can live for up to 5 years but, in our laboratory, typically show greatly reduced fertility after 18 months. The fish become fertile after around 3 months of age, so we regard 6-month-old fish as equivalent to young adult humans. Therefore we analysed the transcriptomes of entire young adult, 6-month-old fish brains using poly-A enriched RNA-seq technology, and estimated gene expression from the resulting single-end $75 \mathrm{bp}$ reads using the reference GRCz11 zebrafish assembly transcriptome [11, 12]. Each zebrafish brain has a mass of approximately $7 \mathrm{mg}$. Since $\mathrm{AD}$ is more prevalent in human females than males, and to further reduce gene expression "noise" in our analyses, we obtained brain transcriptome data from four female wild type fish and four female heterozygous mutant fish. This data has been made publicly available at the Gene Expression Omnibus (GEO, see under Availability of data and materials below).

\section{Results}

\section{Differentially expressed genes (DE genes)}

Genes differentially expressed between wild type and heterozygous mutant sibling fish were identified using moderated $t$-tests and a false discovery rate (FDR)-adjusted $p$-value cutoff of 0.05 as previously described $[9,13,14]$. In total, 251 genes were identified as differentially expressed (see Additional file 1). Of these, 105 genes showed increased expression in heterozygous mutant brains relative to wild type sibling brains while 146 genes showed decreased expression.

\section{GO analysis}

To understand the significance for brain cellular function of the differential gene expression identified in young adult heterozygous mutant brains we used the goana function [15] of the limma package of Bioconductor software [14] to identify GOs in which the DE genes were enriched at an FDR-corrected $p$-value of less than 0.05. Seventy-eight GOs were identified (Table 1) of which 20 addressed cellular components (CC). Remarkably, most of these CCs concerned the mitochondrion, membranes, or ATPases. Seventeen GOs addressed molecular functions (MF) and largely involved membrane transporter activity, particularly ion transport and ATPase activity coupled to such transport. Forty-one GOs addressed biological processes (BP) and involved ATP metabolism, ribonucleoside metabolism, and transmembrane transport processes including vacuolar acidification (that has previously been identified as affected by EOfAD mutations in PSEN1 [16]). Overall, our GO analysis indicates that this EOfAD-like mutation of zebrafish psen 1 has very significant impacts on cellular energy metabolism and transmembrane transport processes.

\section{Additional file}

\begin{abstract}
Additional file 1: Genes differentially expressed between heterozygous mutant and wild type brains at 6 months. Lists the genes identified as differentially expressed between the brains of heterozygous psen ${ }^{\text {Q96_K97del }}$ mutant fish and the brains of their wild type siblings at an age of 6 months. Genes are ranked according to FDR-corrected $p$-value. Only genes with a FDR-corrected p-value less than 0.05 are shown. "FC" denotes fold change. "DE" denotes differential expression. For DE_Direction, "1" denotes increased expression in the mutant and "-1" denotes decreased expression in the mutant. (XLSX 39 kb)
\end{abstract}

\section{Abbreviations}

AD: Alzheimer's disease; ATP: Adenosine triphosphate; BP: Biological process (GO term); CC: Cellular component (GO term); DE genes: Differentially expressed genes; EOfAD: Early onset familial Alzheimer's disease; FDR: False discovery rate; GEO: Gene Expression Omnibus; GO: Gene ontology; MAPT: MICROTUBULEASSOCIATED PROTEIN TAU (human protein); MF: Molecular function (GO term); mg: Milligrams; MRI: Magnetic resonance imaging; PSEN1: PRESENILIN 1 (human gene); PSEN1: PRESENILIN 1 (human protein); psen 1: presenilin 1 (zebrafish gene); Psen1: Presenilin 1 (zebrafish protein)

\section{Acknowledgements \\ The authors wish to thank the Carthew Family Foundation and Prof. David Adelson for their encouragement and support.}

\section{Funding}

This work was supported by grants from Australia's National Health and Medical Research Council, GNT1061006 and GNT1126422, and from the Carthew Family Foundation. 


\section{Availability of data and materials}

The datasets generated and/or analysed during the current study are available in the GEO repository (https://www.ncbi.nlm.nih.gov/geo/) under accession number GSE126096.

psen 1 ${ }^{\text {Q96_K97del }}$ mutant zebrafish are available upon request. However, due to Australia's strict quarantine and export regulations, export of fish involves considerable effort and expense and these costs must be borne by the party requesting the fish.

\section{Authors' contributions}

MN conceived the project, sought funding, generated the psen $1^{\text {Q96_K }}$ (97del mutant zebrafish, identified the genotype of individuals, and isolated mRNA from zebrafish brains. NH processed the RNA-seq data and performed bioinformatics analysis to identify DE genes and GOs. SP supervised the work of $\mathrm{NH}$ and performed data quality checks. ML conceived the project, sought funding, coordinated the project, and drafted this research report. All authors contributed to interpretation of data and to reviewing and editing drafts of the submitted manuscript. All authors read and approved the final manuscript.

\section{Ethics approval and consent to participate}

This study was conducted under the auspices of the Animal Ethics Committee of the University of Adelaide, under permits S-2014-108 and S-2017-073.

\section{Consent for publication}

Not applicable.

\section{Competing interests}

The authors declare that they have no competing interests.

\section{Publisher's Note}

Springer Nature remains neutral with regard to jurisdictional claims in published maps and institutional affiliations.

Received: 4 February 2019 Accepted: 24 April 2019

Published online: 03 May 2019

\section{References}

1. Jayne T, Newman M, Verdile G, Sutherland G, Munch G, Musgrave I, et al. Evidence for and against a pathogenic role of reduced gamma-Secretase activity in familial Alzheimer's disease. J Alzheimers Dis. 2016;52(3):781-99.

2. Jack CR Jr, Bennett DA, Blennow K, Carrillo MC, Dunn B, Haeberlein SB, et al. NIA-AA research framework: toward a biological definition of Alzheimer's disease. Alzheimers Dement. 2018;14(4):535-62.

3. Hargis KE, Blalock EM. Transcriptional signatures of brain aging and Alzheimer's disease: what are our rodent models telling us? Behav Brain Res. 2017;322(Pt B):311-28.

4. Neuner SM, Heuer SE, Huentelman MJ, O'Connell KMS, Kaczorowski CC. Harnessing genetic complexity to enhance translatability of Alzheimer's disease mouse models: a path toward precision medicine. Neuron. 2019; 101(3):399-411 e5.

5. Guo Q, Fu W, Sopher BL, Miller MW, Ware CB, Martin GM, et al. Increased vulnerability of hippocampal neurons to excitotoxic necrosis in presenilin-1 mutant knock-in mice. Nat Med. 1999;5(1):101-6.

6. Siman R, Reaume AG, Savage MJ, Trusko S, Lin YG, Scott RW, et al. Presenilin-1 P264L knock-in mutation: differential effects on abeta production, amyloid deposition, and neuronal vulnerability. J Neurosci. 2000; 20(23):8717-26.

7. Ryman DC, Acosta-Baena N, Aisen PS, Bird T, Danek A, Fox NC, et al. Symptom onset in autosomal dominant Alzheimer disease: a systematic review and meta-analysis. Neurology. 2014;83(3):253-60.

8. Quiroz YT, Schultz AP, Chen K, Protas HD, Brickhouse M, Fleisher AS, et al. Brain imaging and blood biomarker abnormalities in children with autosomal dominant Alzheimer disease: a cross-sectional study. JAMA Neurol. 2015;72(8):912-9.

9. Hin N, Newman M, Kaslin J, Douek AM, Lumsden A, Xin-Fu Z, et al. Accelerated brain aging towards transcriptional inversion in a zebrafish model of familial Alzheimer's disease. bioRxivorg. 2018.

10. Cruts M, Theuns J, Van Broeckhoven C. Locus-specific mutation databases for neurodegenerative brain diseases. Hum Mutat. 2012;33(9):1340-4.
11. Bray NL, Pimentel H, Melsted P, Pachter L. Near-optimal probabilistic RNAseq quantification. Nat Biotechnol. 2016;34(5):525-7.

12. Zerbino DR, Achuthan P, Akanni W, Amode MR, Barrell D, Bhai J, et al. Ensembl 2018. Nucleic Acids Res. 2018;46(D1):D754-D61.

13. Law CW, Alhamdoosh M, Su S, Dong X, Tian L, Smyth GK, et al. RNA-seq analysis is easy as 1-2-3 with limma, Glimma and edgeR. F1000Res. 2016;5:1408.

14. Ritchie ME, Phipson B, Wu D, Hu Y, Law CW, Shi W, et al. Limma powers differential expression analyses for RNA-sequencing and microarray studies. Nucleic Acids Res. 2015;43(7):e47.

15. Young MD, Wakefield MJ, Smyth GK, Oshlack A. Gene ontology analysis for RNA-seq: accounting for selection bias. Genome Biol. 2010;11(2):R14.

16. Lee JH, Yu WH, Kumar A, Lee S, Mohan PS, Peterhoff CM, et al. Lysosomal proteolysis and autophagy require presenilin 1 and are disrupted by Alzheimer-related PS1 mutations. Cell. 2010;141(7):1146-58.

\section{Ready to submit your research? Choose BMC and benefit from:}

- fast, convenient online submission

- thorough peer review by experienced researchers in your field

- rapid publication on acceptance

- support for research data, including large and complex data types

- gold Open Access which fosters wider collaboration and increased citations

- maximum visibility for your research: over $100 \mathrm{M}$ website views per year

At BMC, research is always in progress.

Learn more biomedcentral.com/submissions 